\title{
Regaining momentum
}

I n 1994, after 15 years of nonstop, sedentary postsecondary education, I vowed to learn a new sport every winter and every summer. So, in the winter of 2003, I set out to learn indoor rock wall climbing with my trainer and her friend. On my fifth ascent, I signalled when I had reached the top of the climb and assumed the seated position, ready to descend.

The decent was slow at first. The pink stucco wall with its protruding holds passed upward in front of me. Then I dropped. I lost consciousness as I fell 15 feet. I awoke on my back, legs spayed wide, arms wide, far from the wall. My requests for an ambulance were ignored. I was told by the floor monitor to get up and out of the way, as I had become a danger to other climbers.

I was wobbly on my legs, and my head was spinning: I struggled to manage a powerful headache. I felt an enormous bump on the back of my head. I later learned that I had landed on my coccyx, compressing my spine upward, and had then sprung backward and hit the back of my head on the support beam joinery beneath the lightly padded floor. I had suffered a concussion and brain trauma, followed by amnesia and a host of other injuries, which gradually emerged. Coping with my symptoms entailed a heavy calendar of medical appointments, especially during the first three years. The magnetic resonance imaging and computed tomography, the invasive testing, the painful physiotherapy sessions and what seemed like incessant poking and prodding wore at my selfesteem. And the relentless appointments meant I couldn't sustain my busy family law litigation practice.

I ached for calm and normalcy. It didn't come. I switched from litigation to the more predictable and calmer pace of a collaborative family law practice. I wanted to immerse myself in this new interest, but it was incredibly difficult. Beyond my own medical challenges, the love of my life was

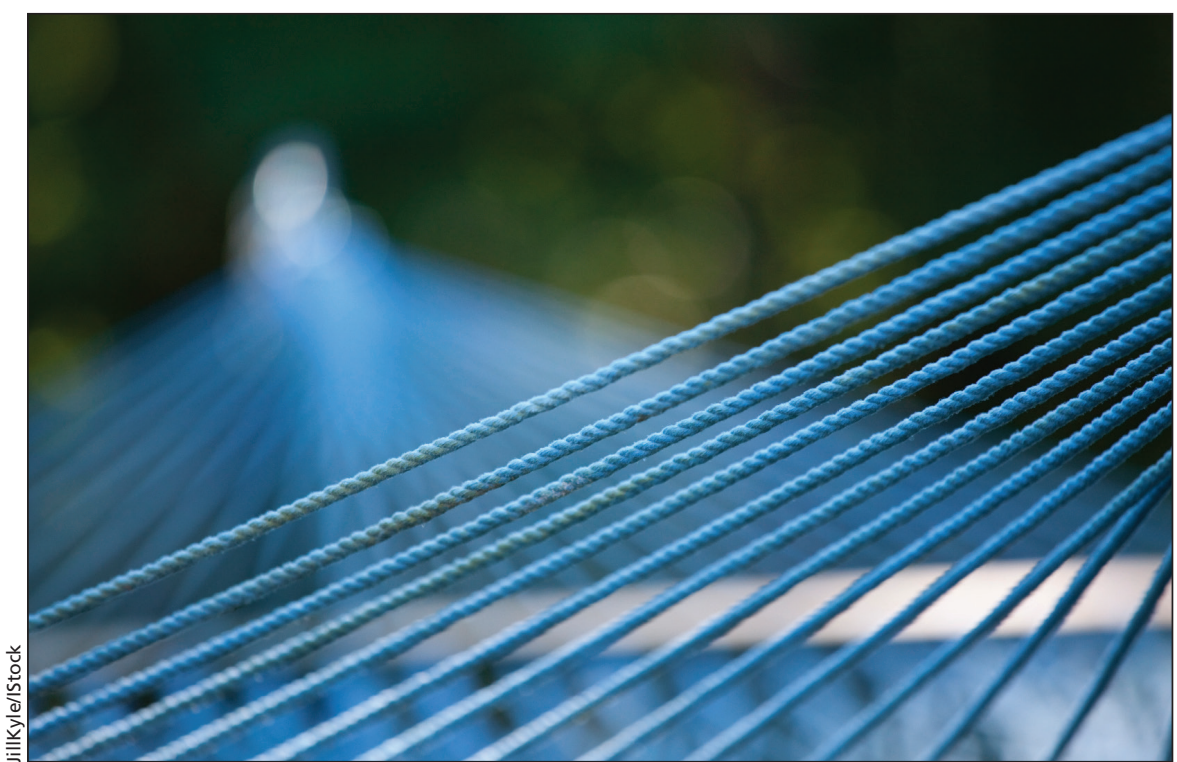

fighting an illness, while I wrestled with post-traumatic stress, which was not understood by friends or colleagues. I sought to keep the pain, both physical and emotional, to myself and to concentrate on maintaining my law firm, now on a part-time basis.

Then, three years after the accident, a new symptom emerged. I began to fall over to my right side. It was the result of a damaged nerve deep in my right ear. If I stood very still or walked steadily forward on a flat surface, I would remain upright. If I moved in any other direction - up, down, right, left or on any gradient - I would fall over to the right. The injury was traced back to the climbing incident. I was told by the neurologist, "There isn't a pill for mobility intolerance. You just have to live with it!"

I was incredulous at this prognosis.

After years of physical training, I couldn't hold my balance simply to walk. I tried using visualization, seeing myself moving confidently, but it didn't work. I realized I needed to rethink the problem. If the problem was mobility intolerance, how could I gain mobility tolerance? I understood that the neural message from my eyes needed to be compatible with the messages being sent from my ear. The question became: How could I retrain the neural pathways to regain my balance? How could I regain tolerance for movement?

I am visually and kinetically cued. I tried to imagine what exercises or devices would help me. I started with standing and balancing on one foot. I tried some gentle yoga moves, without success. Some things that I tried left me flailing, falling over. Fifteen months after the diagnosis, my frustration was high, but the motivation to find a cure was greater. In March, I was daydreaming of the warmth of the spring sun on my face. I stared at my back garden as it was starting to bud. And then the answer appeared: my hammock. I could swing in any direction while lying perpendicular to the hammock or parallel to it. Its netting would give me strong finger holds to support myself.

Despite the cold and snow that day, I set up the hammock in my backyard. I started with simply watching it sway. When the nausea built to an unbearable level, I closed my eyes. Sometimes I fell over because I let the nausea build up too much - I was so eager to put an end to the vertigo. I admitted that I needed to calm myself and work at this project over a longer 
period of time. I also realized that I need to incorporate a day or two of rest time into every week.

Once I could handle watching the hammock swaying, I practised trying to sit down in it. That was harder than I thought it would be, because of the other injuries I had suffered.

When I finally was able to sit, I enjoyed that little victory. I looked from side to side, taking in the new experience of managing the subtle motion of simply sitting on a hammock. There was always some movement to handle. On the coldest days, I used an exercise ball indoors near an inner corner at the gym. That placement of the ball would allow me to fall into a wall without getting hurt. I faced away from the walls and focused my eyes on a single spot on a far wall as I stood and sat. Some days I could manage only three tries, and that was fine. I expected some defeat.

When I was able to stand and sit on the hammock or ball a dozen times without any nausea, I moved on to swaying back and forth on the hammock or rolling on the ball while seated. Again, I made only a small movement at first, using my feet to control the momentum.

The hammock was in motion, and I was in motion. I would practise on the hammock until the nausea came on. That would be enough for one day. I reasoned that my senses were exhausted and overwhelmed as they were rewiring. A pause was okay.
Repeating the same subtle movement was okay. Very gently and very slowly, the vertigo was fading and disappearing from some ambulatory functions. Over four months, I progressed from just being able to sit and stand at a very slow pace to being able to lie down and return to a standing position. Some days just being able to sit on the hammock and experience my body balancing to stay upright was a big accomplishment.

From there, my goal was to lie down on my right side, the side of the injured ear. I gingerly lay down parallel with the length of the hammock and swung almost imperceptibly at first, my toe anchored to the ground to maintain control. The simple act of getting from a seated position to lying parallel was both exciting and frightening. When I mastered that, I shifted to lying perpendicular. Two years after the diagnosis, I progressed to moving from one side to the other, then to my back and onto my stomach. I built height into my swings. No nausea crept over me. The absolute joy of my unimpeded and cherished mobility was finally achieved.

\section{Lorisa Stein MA JD}

Barrister and solicitor, family law lawyer, Toronto, Ont.

This article has been peer reviewed.

This is the author's story.

CMAJ 2016. DOI:10.1503/cmaj.160281

"Imagination is more important than knowledge. For knowledge is limited, whereas imagination embraces the entire world, stimulating progress, giving birth to evolution." - Albert Einstein 